\title{
Strategy of Aesthetic Laser Removal of Multiple Seborrheic Keratosis and Effects on Appearance' Self-Esteem and Well-Being
}

\author{
Julian Penev', Milla Balabanova², Ilko Bakardzhiev ${ }^{3 *}$ \\ ${ }^{1}$ MU Varna Dept. Infections and Skin Diseases, Varna, Bulgaria \\ ${ }^{2}$ VFU Chernorizetz Hrabar SDK Psychology, Varna, Bulgaria \\ ${ }^{3}$ MU Varna, Medical College, Varna, Bulgaria
}

Received: August 20, 2019; Accepted: September 14, 2019; Published: September 27, 2019

*Corresponding author: Milla Balabanova, PhD, VFU Chernorizetz Hrabar SDK Psychology, Varna, Bulgaria. Email: millybalabanova@gmail. com

\begin{abstract}
Background: Individual well-being and self-esteem related to appearance of patients with multiple seborrheic keratoses (MSK), as well as an original strategy for complete removal of all lesions with $\mathrm{CO}_{2}$ laser are discussed. Presented are examples from our dermatological practice illustrating negative psycho-social impact of multiple SK on individual well-being. Seborrheic keratosis is considered a widespread dermatosis, as well as a cosmetic issue for its presence creates an overall impression of prematurely aged, and a "shabby" looking skin. Individuals with multiple SK often suffer low self-esteem in terms of their appearance which may improve after the aesthetic $\mathrm{CO}_{2}$ laser complete elimination of MSK lesions.
\end{abstract}

Objective: To study if appearance related self-esteem improves after the aesthetic $\mathrm{CO}_{2}$ laser full removal of the multiple SK lesions located on face and trunk areas. For the purpose, changes in appearance' self-esteem post laser removal of multiple SK are tested.

Methods: Therapeutic and aesthetic removal of multiple SK is accomplished by laser thermolysis performed with $\mathrm{CO}_{2}$ laser, in particular Study participants are asked to fill out a Self-Assessment of appearance' self-esteem (11 items questionnaire) twice - before the complete $\mathrm{CO}_{2}$ laser removal of MSK, and then six months post the aesthetic laser treatment, as answers reflect patient subjective understanding of the degree of their physical attractiveness. Statistics performed using IBM SPSS Statistics, version 20. One hundred volunteers with multiple SK on face, and trunk took place in the study.

Results: In both before and after measurements show that Appearance' self-esteem scale distribution is close to normal distribution; Cronbach's alpha 0.81 , and then 0.61 , respectively. No gender differences observed $(M=2.45, S D=0,56)$ female $(M=2.59, S D=0.57) ; t=-1.077, p=0.284$, and males $(\mathrm{M}=3.86, \mathrm{SD}=0.28)$, females $(\mathrm{M}=3.86, \mathrm{SD}=0.38) ; \mathrm{t}=0.077, \mathrm{p}=0.939$.

Conclusions: Complete aesthetic $\mathrm{CO}_{2}$ laser removal of multiple sebborheic keratosis from face and trunk improves self-esteem related to appearance. The described original $\mathrm{CO}_{2}$ treatment strategy serves as a practical tool in aesthetic removal of multiple seborrheic keratoses.

Key words: Seborrheic keratosis; Multiple seborrheic keratosis; $\mathrm{CO}_{2}$ laser thermolysis; Appearance related self-esteem; Individual well-being;

\section{Introduction}

Skin diseases are far more than just a cosmetic issue, and numerous questions related to therapeutic, aesthetic, and psychosocial dimensions of appearance need to be addressed in terms of improving individual well-being of those affected. Understanding psyche-skin relationships is to be of particular importance to dermatology specialists, as skin constitutes an integral part of one's own appearance, and the way patients perceive, approve or disapprove their own appearance affect the way they feel about themselves, their sense of self-esteem, social confidence, interpersonal relationships and psycho-social functioning, and individual well being, respectively [3]. To achieve adequate assessment and understanding of individual well-being of patients with skin diseases is however, a somehow difficult task, due to a certain degree to patients' own subjective perception and interpretation of the severity of the disease, and experienced negative impact on the physical and psycho-social functioning. Besides general concerns about skin and overall health condition, a lowered self-esteem, perception of a compromised appearance, lack of social confidence, and worries about how unattractive they might look in other people's eyes are quite typical for skin sufferers [4]. Body image projection on overall self esteem, psycho-social functioning, and individual well-being of people with skin diseases and conditions, including seborrheic keratosis thus, need to be studied further.

Scientific literature provides sufficient data on skin diseases and conditions such as seborrhoeic dermatitis, rosacea, couperose, melasma, acne, eczema, psoriasis, etc. to have a negative impact on quality of life $[1,6,9,10]$. Study findings that provide evidence on severe consequences of psoriasis on self-esteem, and quality of life are comprehensive. This is due to the fact that psoriasis is so wide spread. Yet, seborrheic 
keratosis (SK) is perhaps even more prevalent than psoriasis. Quite conspicuous and visible, SK is considered benign epidermal parakeratosis, and abnormal ripening of the epidermis. Dermatologists define it as benign, noncancerous dermatosis, as well as a pronounced cosmetic imperfection since it gives the impression of prematurely aged and a "shabby" looking skin [7]. MSK appears predominantly on face, neck, and trunk of the body. It is generally assumed that SK is a senile dermatosis [5], typically seen in elderly individuals. In our practice we also observed SK occurrence in individuals with hyper hygienic habits and sun over exposure on a regular basis [7]. One can develop SK at any age, yet causes for the appearance of SK remain unknown, and controversial. SK etiology is considered idiopathic, although a possible family and hereditary predispositions are discussed for people with lighter shade skin in Caucasian, and African races. A variation of SK - DPN (Dermatosis Papulosa Nigra) presents with multiple pigmented lesions on the face and around the eyes; may be present as early as in the second decade of life, and is most likely of a hereditary nature. Colloquially known either as "liver" or "senile spots" SK lesions are being wrongly yet popularly associated by many people with digestive tract, and/or liver dysfunction problems[11]. SK presence primarily on the face affects both self-esteem, and psychosocial comfort of the affected [10]. This is quite understandable, since seborrheic keratosis often manifests via multiple (cluster like) lesions, as its eruptions can reach up giant dimensions (up to 9-10 cm). Many SK sufferers also get concerned regarding a possible malignancy, which further creates a state of fear or anxiety especially when a lesion gets darker in color or inflamed in body areas with increased sweating and friction - under the breast, arm and inguinal folds areas, in particular. Furthermore, ignorant beliefs like SK is being contagious and its presence, and removal of SK lesions pose fatal consequences are widespread. Actually, this could be explained with the fact that SK gets often mistaken by many people for other dangerous dermatoses, exhibiting at the very first glance characteristics that look similar to those of SK (i.e. malignant melanoma, lentigo maligna, basal cell carcinoma, spinocellular carcinoma, etc). Being the most common benign skin tumors, SK' clinical variability can often be confused with malignant diseases [11].

From a dermatological point of view, ill effects of SK on self esteem, and well-being manifest in various ways. In our practice, we have noticed a tendency of using a heavy, multilayered facial foundation and make-up coverage, as well as a purposeful wear of clothing that fully covers the entire body even in the summer by many patients with MSK. Patients themselves report tendency of avoiding bright lighting as they share their feelings of worry and discomfort, and a reluctance to skin touch. Some admit they prefer to present themselves in their most intimate communication setting dressed up, and in dimmed lighting, hoping to make the large SK formations more inconspicuous for the intimate partner. Patients also admit their unwillingness to communicate with people, who seem not to be affected by multiple seborrheic keratosis. These patients disclose they feel unhappy socializing with individuals who present with no apparent similar pigmented lesions on the face and uncovered body parts, for the view of a healthy looking skin makes the MSK sufferers feel even more uncomfortable, and unsecure while socially interacting. Actually, a number of patients with MSK and DPN lesions confess they would rather interact with people, who present with similar skin symptoms. Many report a sense of shame when they have to appear in a lesser clothing - at the swimming pool area, spa treatments, sport activities, etc. Some said they feel discomfort in interaction with their grandchildren who did not want to kiss grandparent cheeks. As overall, most of the patients admit they do not feel physically attractive or just complain mostly about their compromised self-esteem.

Naturally, this study was initially inspired by patients' concerns in regards to their appearance. Patients with MSK complained about their compromised appearance, poor social performance and lack of social confidence in self presentation and in interpersonal relationships with their loved ones, in particular. Some typical examples are presented on (Fig. 1, 2, 3, 4, 5, 6, 7, 8, $9,10,11,12)$. Other factors, however also played an important role in conducting the study: firstly, MSK affected individuals stated few major reasons in regards to their desire to completely eliminate SK manifestations from their skin look: the desire to have a positive self body image and approval of their appearance, enhanced physical attractiveness, a better sense of self-esteem, more confidence in social performance, and in communication with intimate partner and family members. Secondly, a positive feedback from patients post complete aesthetic removal of the lesions served as another contributing factor in conducting the study. They liked to share with us details on their improved well-being (Fig. 6, 6a, 7, 7a, 8, 8a, 9, 9a, 12b). Women, in general communicated about a better sense of self-esteem, feeling more physically attractive, and confident when interacting in family relationships. Some of them reported they stopped using heavily facial make up, and are looking even more youthful. Patients openly communicated about being much happier interacting with their loved ones, as well as feeling more confident to address personal goals as a result to positive changes in their appearance' self esteem, in precise. Others report that the lack of itch after removal of the lesions in friction areas improved their sleep quality (Fig. 3, 3a, 4, 4a).

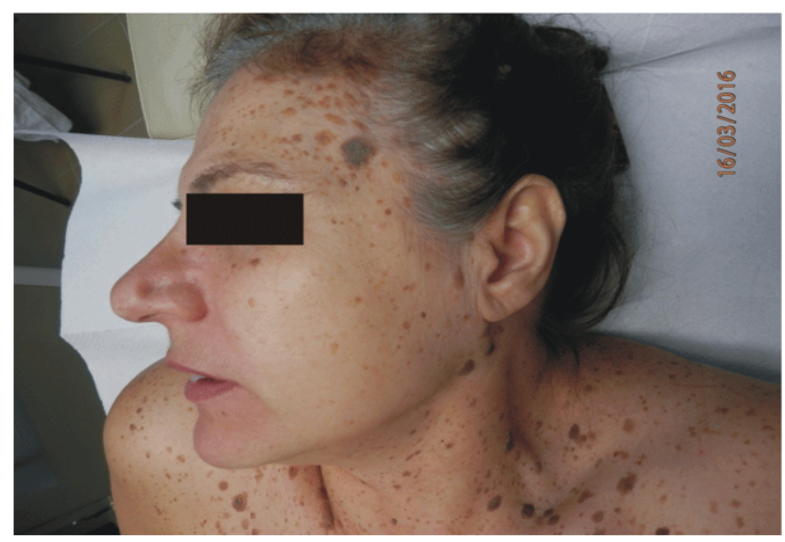

Figure 1: A 55 old female patient with MSK, left side of the face, before treatment 


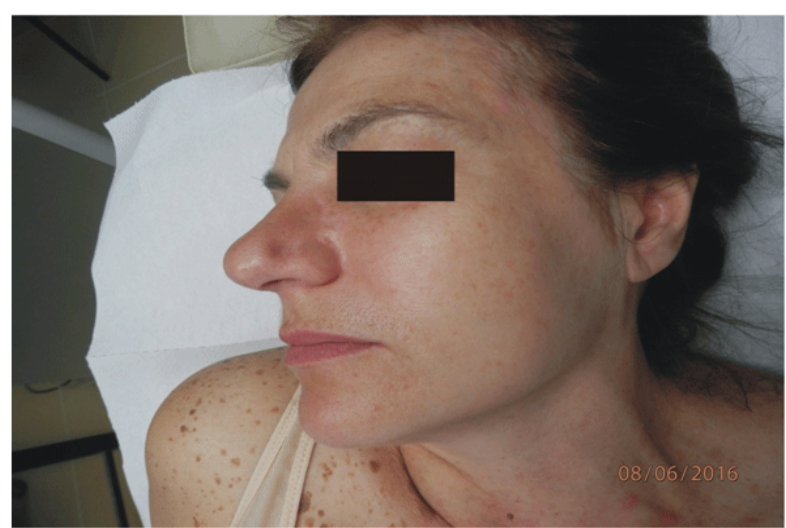

Figure 1a: Same side, 3 months post treatment

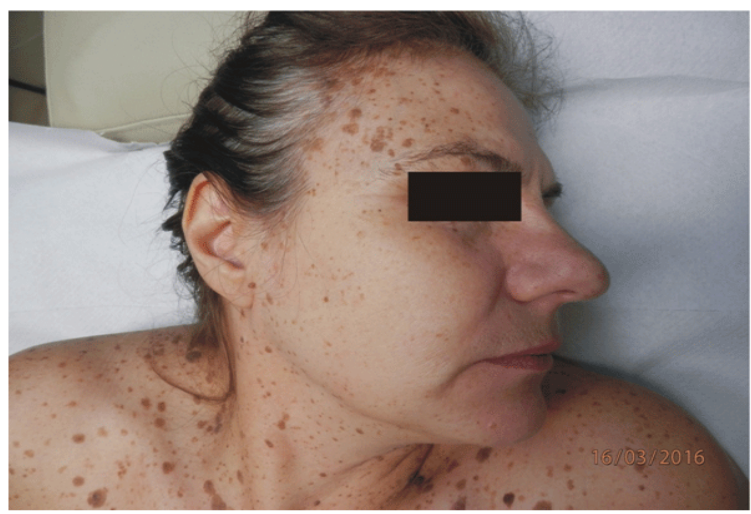

Figure 1b: 3Right side of the face, before treatment

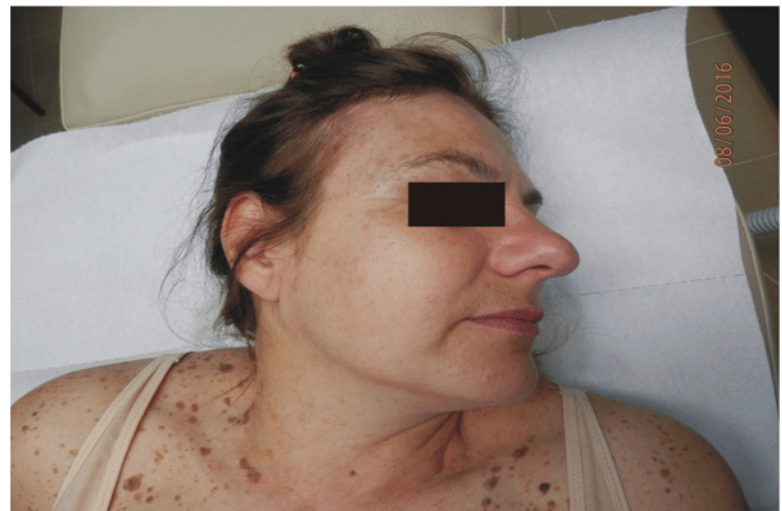

Figure 1c: Result, 3 months post treatment

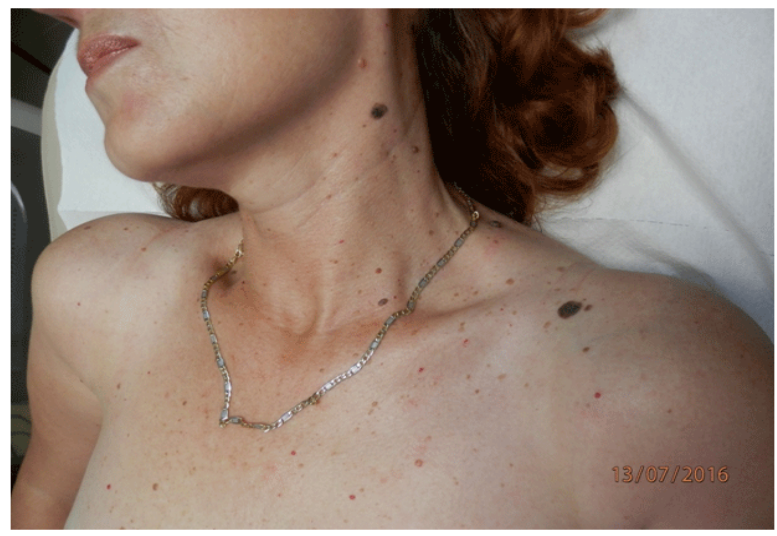

Figure 2: A 55 years old patient, various sizes of SK lesions on neck and neckline, before treatment

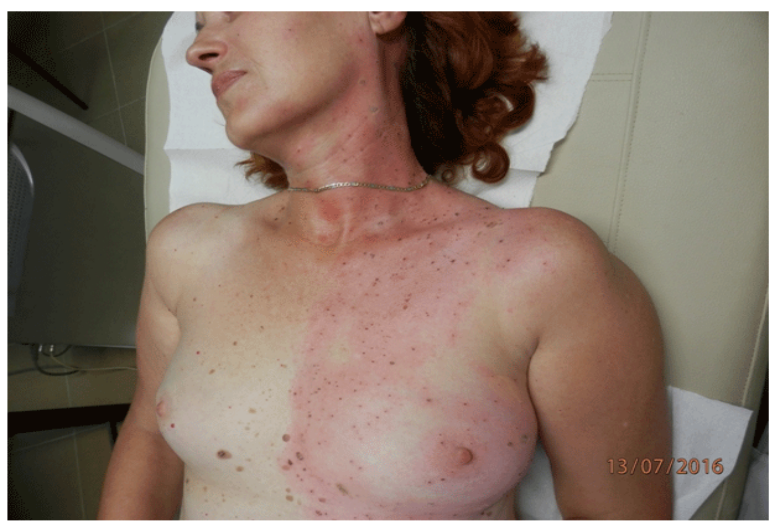

Figure 2a: Immediately after treatment of the left zone. A post treatment erythema is observed around the treated lesions

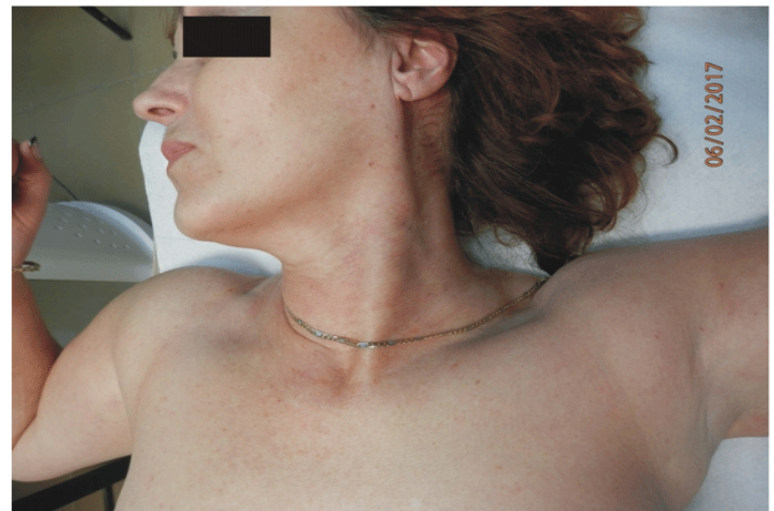

Figure 2b: Six months post total removal of all SK lesions from the neck and neckline area 


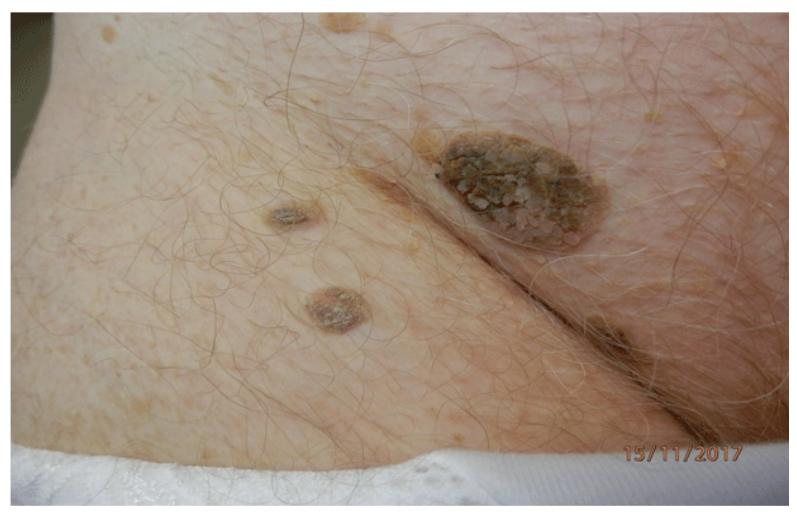

Figure 3: A 69 old female patient with giant SK on inguinal fold. Patient complains of uncomfortable itching which bothers her sleep quality

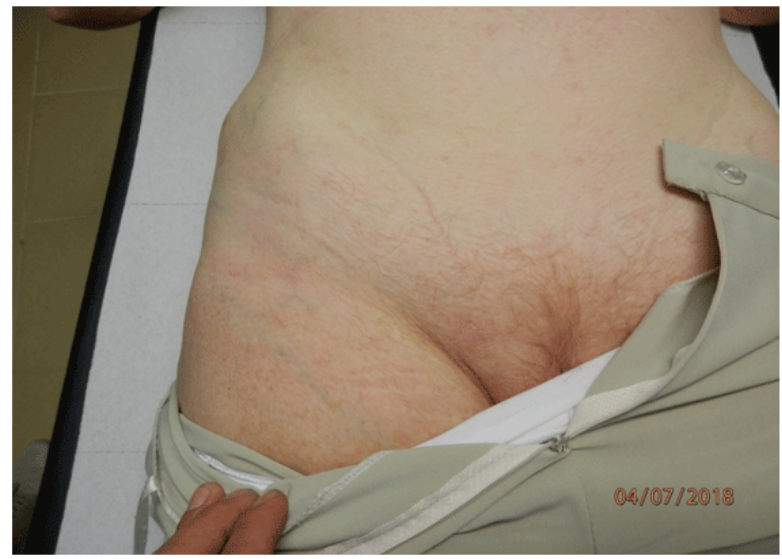

Figure 3a: Six months post treatment. No scarring observed. Patient reports itching is gone

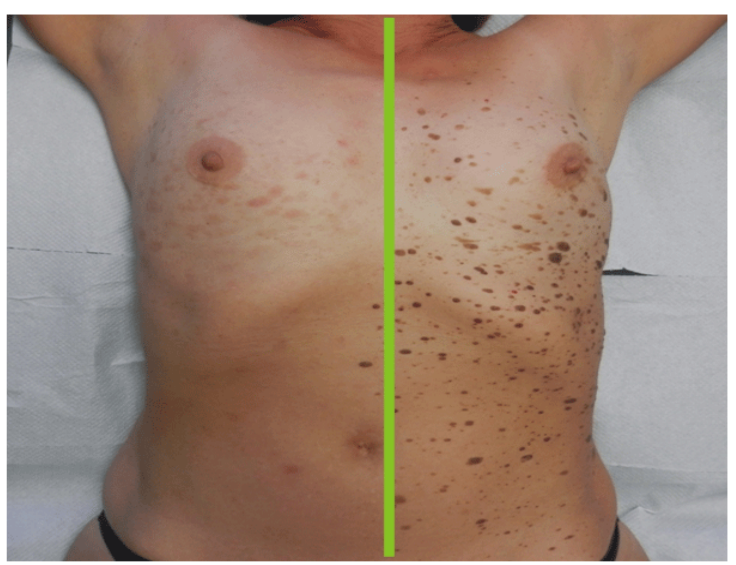

Figure 4: A 56 years old patient, three months after right side treated

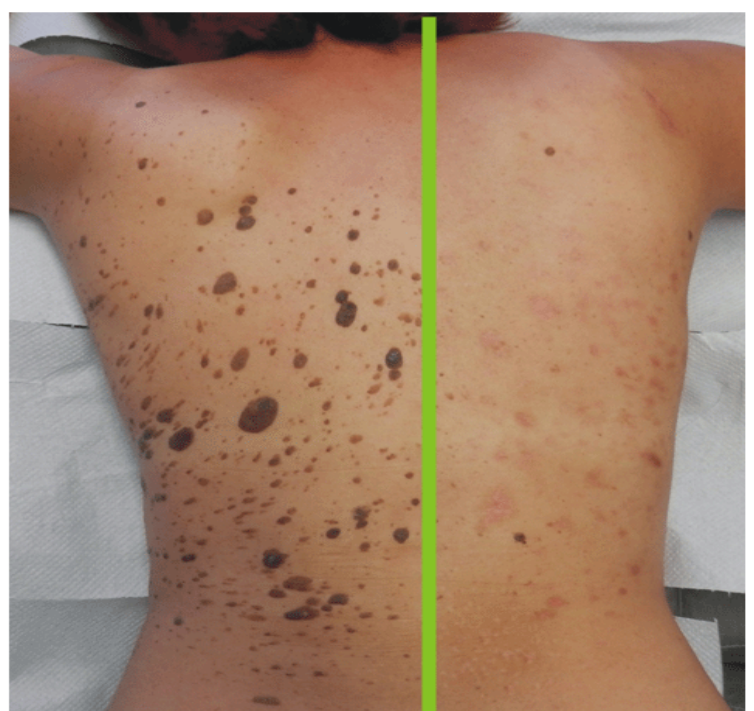

Figure 4a: Same patient' back. Three months post therapy. Slight reddish spots are observed as skin repair process is not yet fully completed

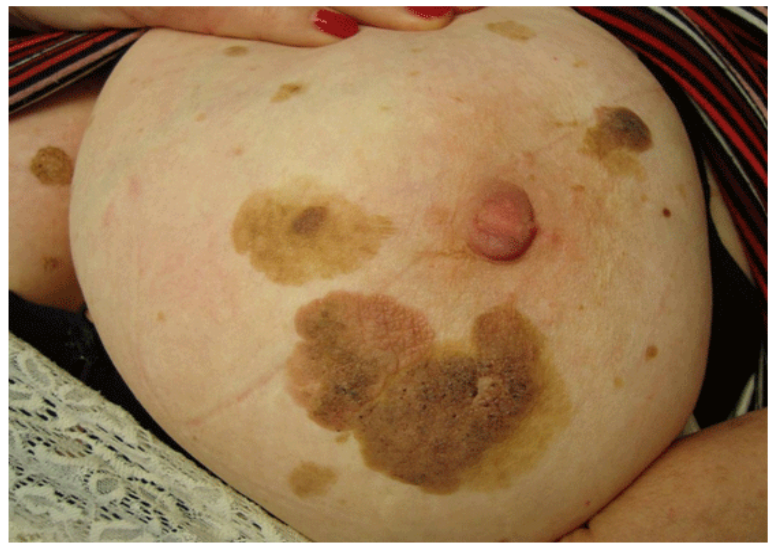

Figure 5: Giant SK on the left breast of the 60 years old patient

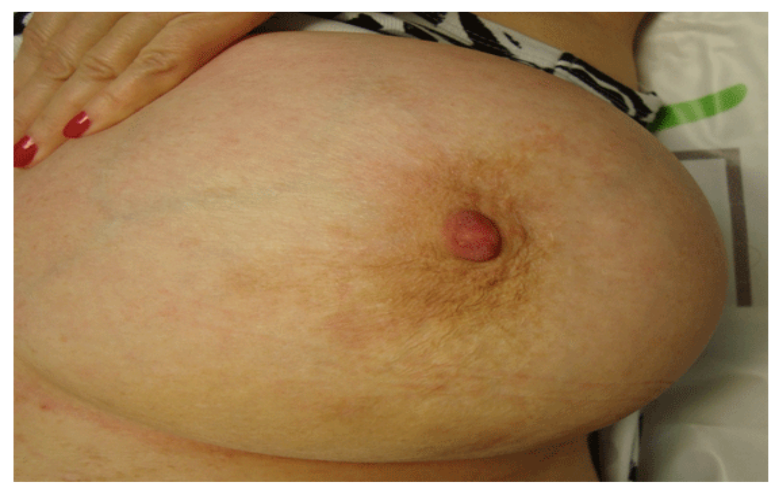

Figure 5a: Six months post treatment. No visible cicatrization or skin depigmenation. Results clearly demonstrate excellent therapeutic and aesthetic advantage of the $\mathrm{CO} 2$ laser treatment method

Citation: Penev J, Balabanova M, Bakardzhiev I (2019) Strategy of Aesthetic Laser Removal of Multiple Seborrheic Keratosis and Effects on Appearance' Self-Esteem and Well-Being. Clin Res Dermatol Open Access 6(4): 1-9. 


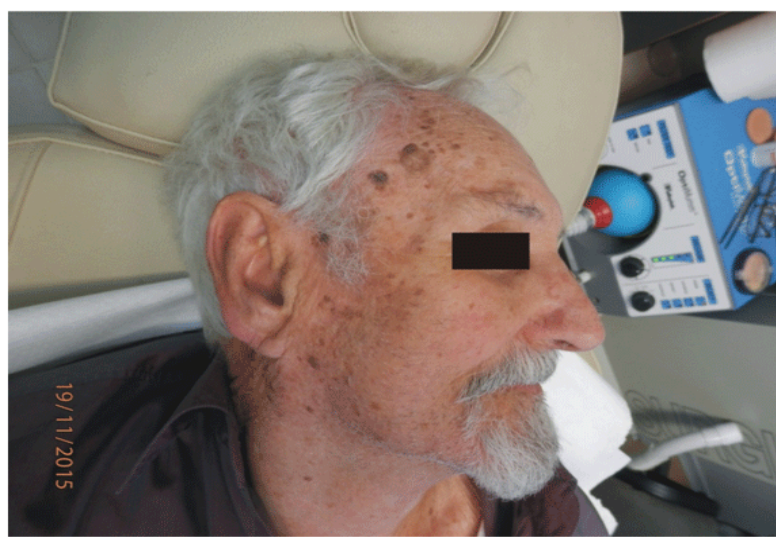

Figure 6: A 75 years old patient with multiple facial SK, creating an impression of an "shabby" skin look

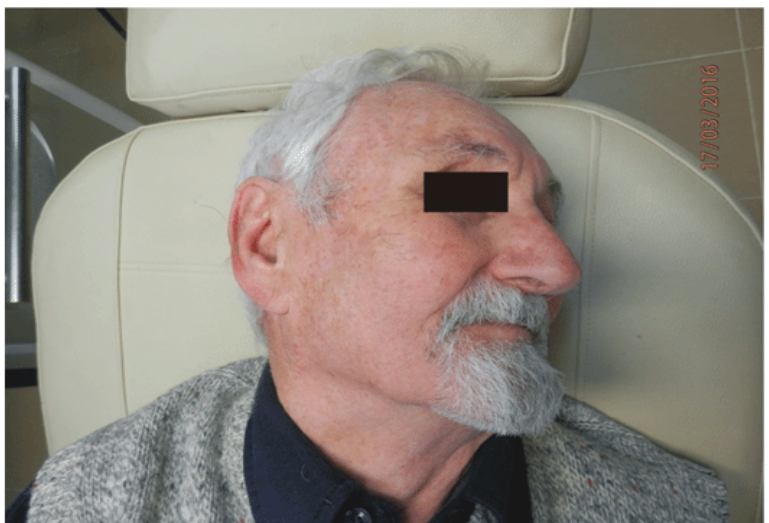

Figure 6a: Four months after therapy. Patient reports a significant improvement in self-esteem and more confidence in family communication

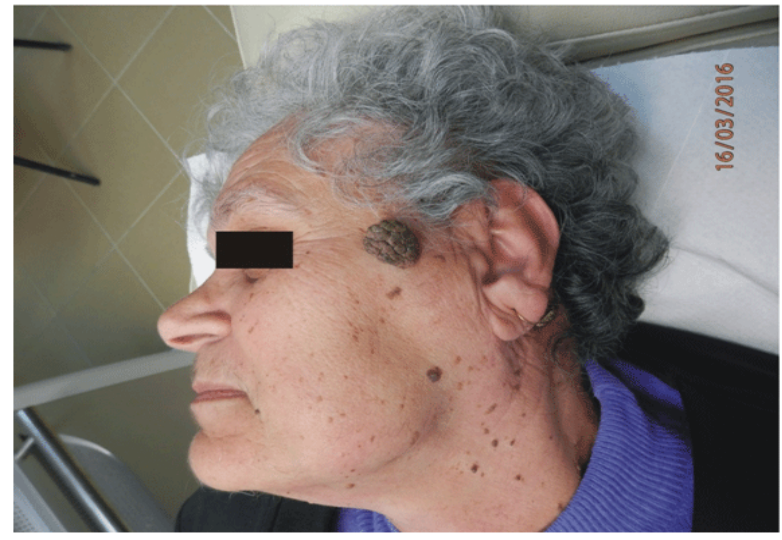

Figure 7: A 70 years old patient with multiple seborrheic keratoses on the face, who shares her grandchildren decline hugging and kissing her

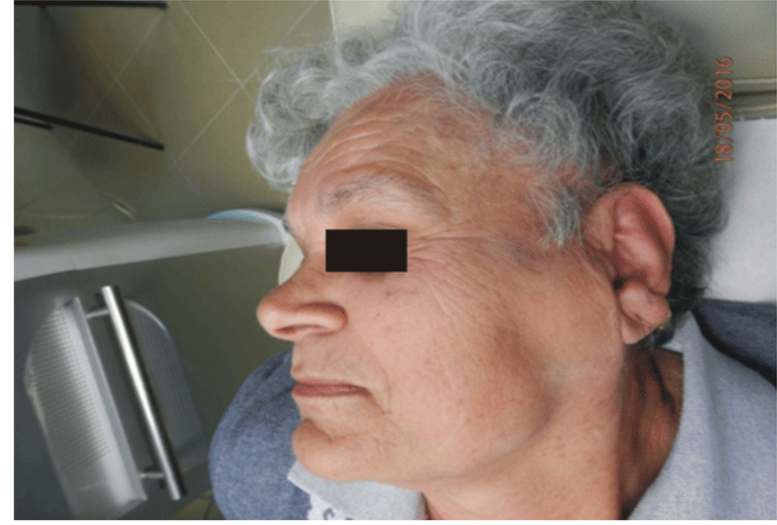

Figure 7a: Two months post therapy, patient reported on improved communication with family members

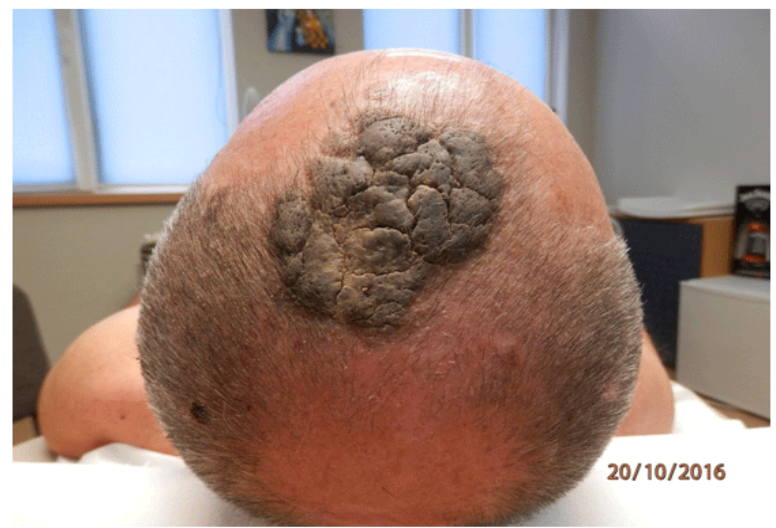

Figure 8: A 70 yaars old patient with giant sebborheic keratosis on his head. Patient confess he always wear a hat and complains doesn't have a confidence to communicate and socialize with other people

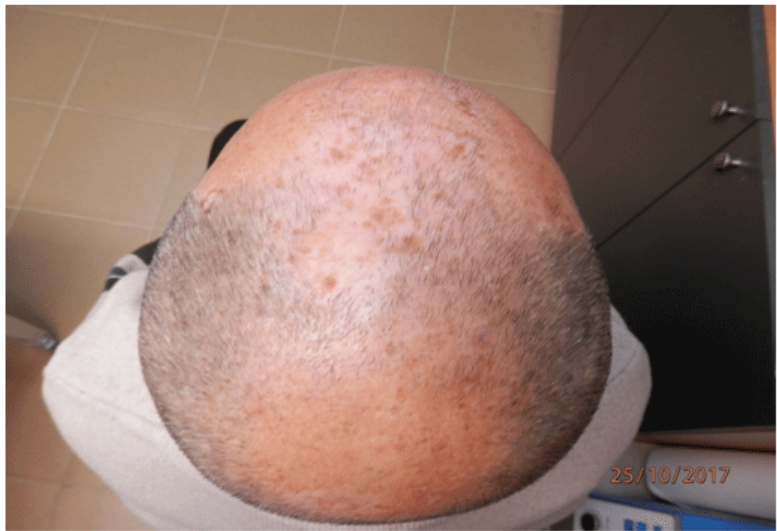

Figure 8a: One year post laser treatment. Observed a delicate scar and some small sized SK recurrences, which are easily removed in one session within the follow-up. Patient reports he feels confident socializing with other people, and participating in social events with no hat on his head.

Citation: Penev J, Balabanova M, Bakardzhiev I (2019) Strategy of Aesthetic Laser Removal of Multiple Seborrheic Keratosis and 


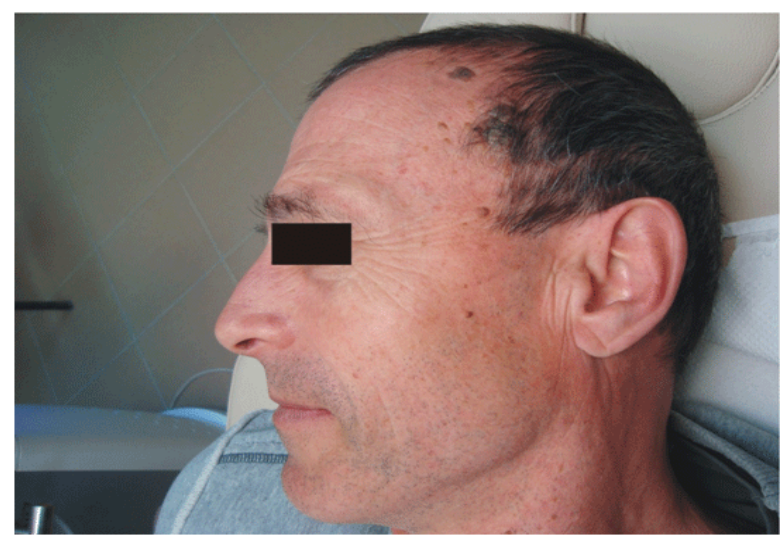

Figure 9: A 59 years old male patient with MSK on forehead. Patient complains he can not put on his professional stage make up, as he feels insecure about his appearance being a professional performer

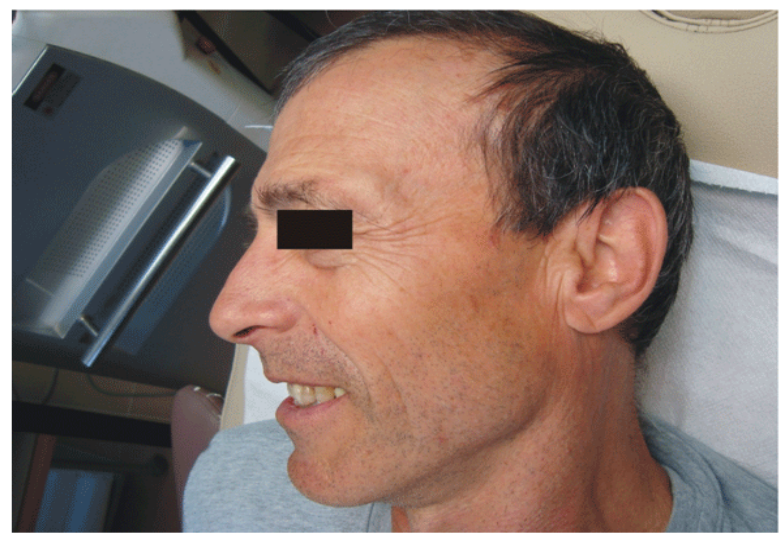

Figure 9a: Six months after treatment. No visible scars observed. Patient reports he is happy with the results achieved

\section{Methods}

A self-evaluation questionnaire - Self Assessment of Appearance Self - Esteem [2], consisting of 11 items, measuring patient individual degree of satisfaction of his/her own physical appearance was distributed to 100 (one hundred) voluntary outpatient participants, 30 male and 70 female patients with MSK lesions on face and trunk. All study participants belong to Caucasian race, are residing on the territory of Bulgaria, age between 30 - 80 years, Fitz patrick' skin types - 1, 2, and 3. All of them voluntarily took participation in the study, and were not financially or otherwise awarded or compensated. Appearance' self-esteem is measured twice; as 1st measurement taken before the complete CO2 laser removal of MSK, and 2nd measurement is taken 6 months after $\mathrm{CO} 2$ laser treatment, in the follow-up frames. Under appearance' self-esteem, a facet of self -esteem which refers to physical appearance is clearly understood. Participating individuals are instructed to do the self-assessing process on a scale from 1 to 5 . Participants choose circling one of the following numbers $-1,2,3,4$ or 5 , the one that most closely corresponds to the way they feel before and after full removal of SK. One is Never, 2- Seldom, 3- Sometimes, 4- Often and 5 Almost Always. Answers reflect patient subjective understanding of their physical attractiveness before removal of MSK and then 6 months post removal, accordingly. ASE assessment form consists of following 11items:

1. I accept critical comments regarding my appearance

2. I look good for my age

3. I do not like myself when staring in the mirror

4. I find specific imperfections that I want to improve, or hide/ camouflage

5. When meeting new people I worry they might pay attention to flaws in my appearance that I do not like myself either

6. I worry how others comment my physical appearance behind my back

7. I look for assessment in regards to how my skin looks from relatives, and friends whom I trust

8. I believe others find my physical appearance appealing

9. I avoid dating because of appearance' flaws concerns

\section{I myself criticize my own appearance}

\section{I get upset any time I think of my facial/ body flaws}

Therapeutic and aesthetic removal of MSK is accomplished by $\mathrm{CO}_{2}$ laser thermolysis and ablation, in particular. Laser thermolysis is a minimally invasive laser technique performed with a $\mathrm{CO}_{2}$ laser, by which lesions are removed on superficial epidermal layers, with minimal deep thermal dermal damage. Used laser technique is a very promising alternative to surgical excision and other traditional (electro coagulation, cryotherapy and chemical destruction methods). It poses low levels risk of complications such as: impetiginization, scarring, depigmentation, kelloids, etc., and presents with outstanding cosmetic results, shown on Fig. 1a, 1c, 2b, 3a, 4a, 5a, 6a, 7a, 8a, 9a, 10b, 11a, 12b. No hospital stay is required. The procedure is bloodless, and high-speeded. In one $10 \mathrm{~min}$. session over hundred small to moderate size lesions can be removed using optimal laser energy density. Some discomfort during procedure is reported to be experienced. No anaesthesia nor antiseptic are required. However, topical anaesthesia can be used for removing giant lesions or in fastidious, and sensitive persons. No topical antibiotic is needed post procedure if no impetiginization. Procedures are spaced in 4weeks apart until complete removal of all lesions. Full check-up is performed at the end of the $6^{\text {th }}$ month when tissue recovery is completed.

Because the lesions are multiple their removal is not possible in one therapeutic session. Therefore, we have created and validated in our practice the following therapeutic strategy. Removal of all MSK lesions is performed on stages. Affected MSK body areas are segmented on treatment zones - left and right, respectively. One area is treated first. For example, the left part of the face or the left part of the body, depending on the lesion density in the area. At the next session, overlooked lesions are being corrected (Fig. 27), and the other (opposite) zone is treated. 


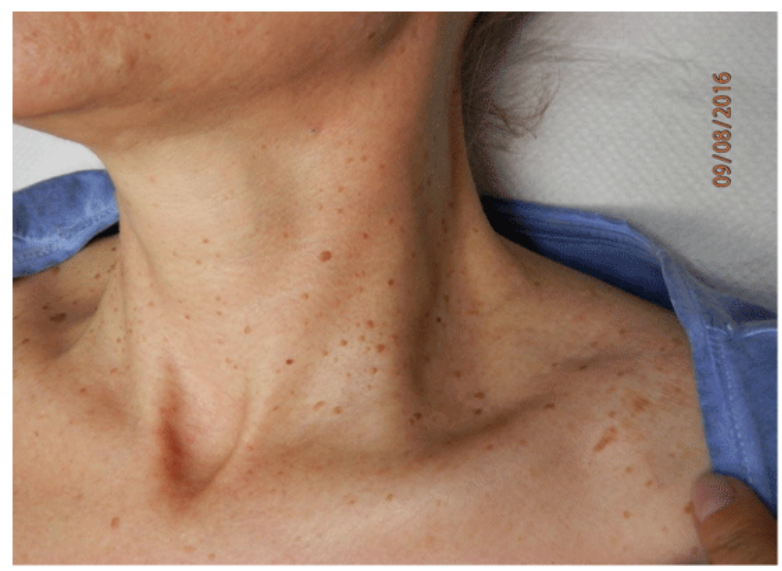

Figure 10: A 57 years old patient with MSK and warts on neck and trunk

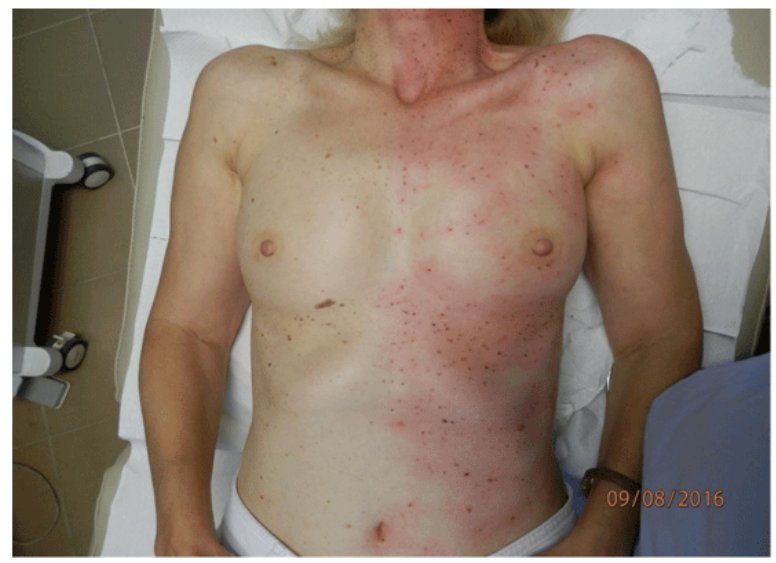

Figure 10a: Immediately after treatment of the left side of the trunk.

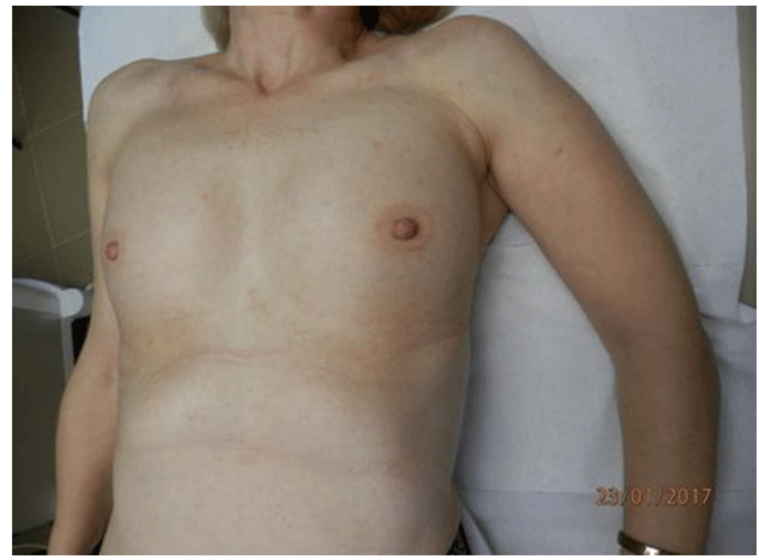

Figure 10b: Six months post CO2 laser removal of MSK from both sides

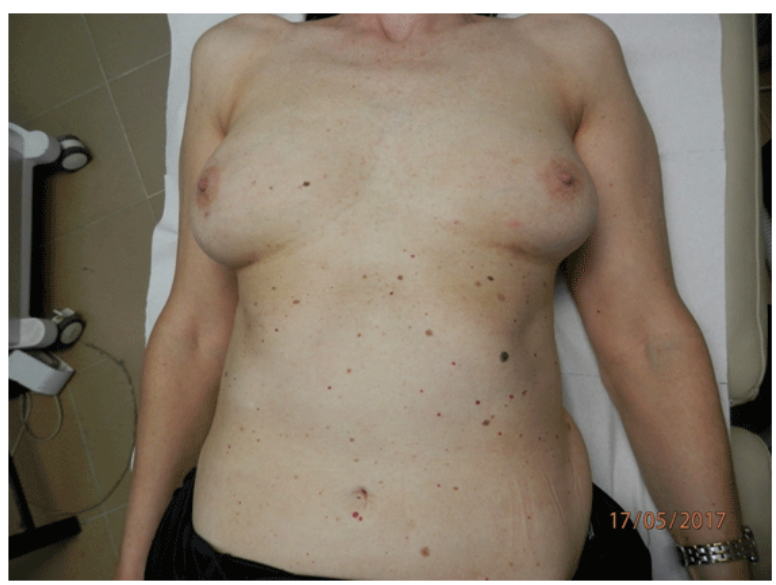

Figure 11: A 50 years old patient before treatment. Patient complains feeling uncomfortable in swimsuit

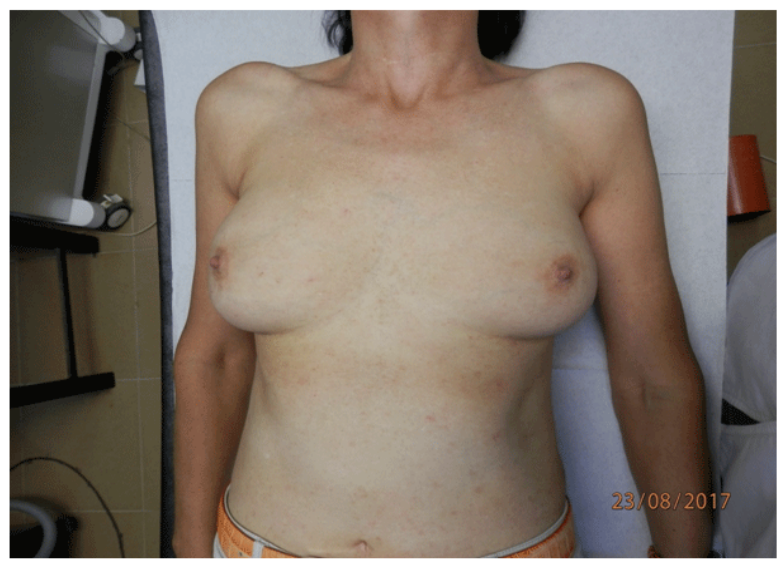

Figure 11a: 3 months post treatment. Missed lesions are to be removed on the following treatment session.

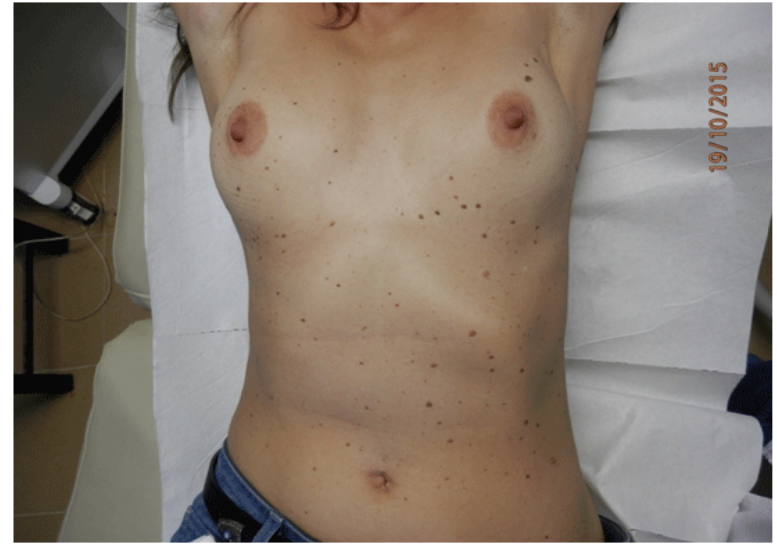

Figure 12: A 57 old patient with MSK on trunk area. Patient likes to sport, complains does not have a confidence to wear sleeveless tops when jogging.

Citation: Penev J, Balabanova M, Bakardzhiev I (2019) Strategy of Aesthetic Laser Removal of Multiple Seborrheic Keratosis and Effects on Appearance' Self-Esteem and Well-Being. Clin Res Dermatol Open Access 6(4): 1-9. 


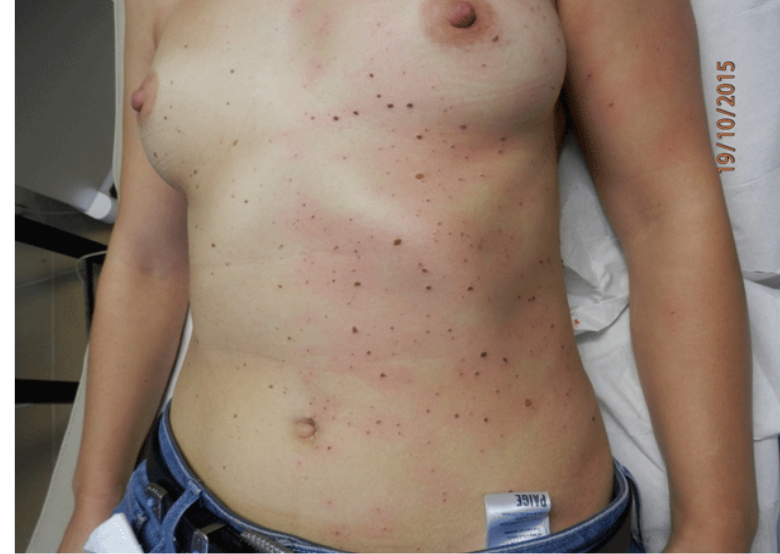

Figure 12a: Immediately after treatment of the left side

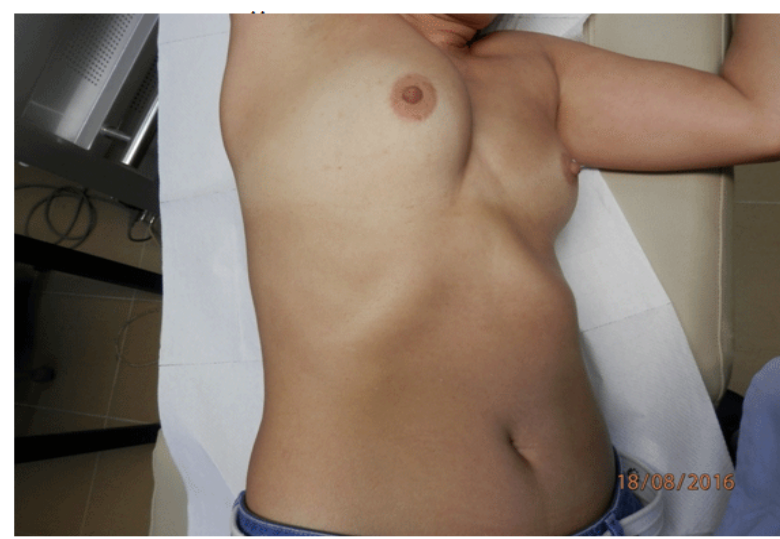

Figure 12b: Final results achieved post complete removal of all SK lesions. Excellent therapeutic and cosmetic results. Patient reported of improved self-esteem in terms of her appearance.

Some examples of this treatment strategy can be seen on (Fig. 2, $4,6,23)$. This technique allows the patients to see differences in their appearance, and differences in the skin look between treated and untreated area, which stimulates them to continue therapy (Fig. 1a, 1c, 2a, 2b, 3a, 7a) [8].

This method also allows the laser specialist to tune finely working laser energy level in an individual dose, most suitable for each individual patient, and type of skin. Procedures are spaced in 4 weeks apart until complete lesion removal. Full check-up is performed at the end of the 6th month after finalization of skin recovery. The technique used has been optimized for more than 30 years. It allows high treatment speed. A relatively wide focal spot ( $>1$ to $3 \mathrm{~mm}$ ) and an average power of $5 \mathrm{~W}$ is used, with the laser in $200 \mathrm{KHz}$ super-pulse mode in $100 \mathrm{~ms}$ pulses and $10 \mathrm{~ms}$ idle. We use a laser system based on the $\mathrm{RF} \mathrm{CO}_{2}$ laser tube Diamont C30 (Coherent), which has very good beam quality in perfect Gaussian TEM00 mode. A brush-like free-hand tehnique is used. Impact duration is controlled by the foot switch. This pulse mode and low laser power density 100-600W/cm2 minimally damage the underlying tissue.

\section{Study Results}

Participating in the study volunteers fill out the ASE questionnaire form twice: at first, before the complete MSK removal, and again - six months post treatment, when they appear for a follow - up. Forms with missing answers are considered invalid, and eliminated. Statistics performed using IBM SPSS Statistics, version 20. Gender distribution presented on Table 1. Descriptive statistics of the appearance' self-assessment for the 1 (first) and 2 (second) measurements (before and after laser therapy, respectively) presented on Table 2. Independent samples t-test results presented on Table 3.

Table1: Frequency and percentage distribution of persons surveyed by gender

\begin{tabular}{|c|c|c|}
\hline Gender & N & \% \\
\hline Men & 30 & 30 \\
\hline Women & 70 & 70 \\
\hline Total & 100 & 100 \\
\hline
\end{tabular}

Table 2: Descriptive statistics of Appearance' Self-assessment Scale -1 st and 2nd measurement (before and post $\mathrm{CO}_{2}$ laser therapy)

\begin{tabular}{|c|c|c|}
\hline & $1^{\text {st }}$ measurement & $2^{\text {nd }}$ measurement \\
\hline $\mathrm{M}$ & 2,55 & 3,86 \\
\hline $\mathrm{SD}$ & 0,79 & 0,53 \\
\hline Skewness & 0,308 & $-0,185$ \\
\hline Kurtosis & $-0,435$ & 0,306 \\
\hline
\end{tabular}

Table 3: Comparison of mean values for the $1^{\text {st }}$ and $2^{\text {nd }}$ measurement of the Appearance' Self-assessment

\begin{tabular}{|c|c|c|c|c|c|}
\hline & $\begin{array}{c}\mathrm{M} \\
(1 \mathrm{st})\end{array}$ & $\begin{array}{c}\mathrm{M} \\
(2 \mathrm{nd})\end{array}$ & Difference & $\mathrm{t}$ & $\mathrm{p}$ \\
\hline $\begin{array}{c}\text { Appearance' } \\
\mathrm{SE}\end{array}$ & 2,55 & 3,86 & $-1,31$ & $-18,993$ & 0,000 \\
assessment & & & & & \\
\hline
\end{tabular}

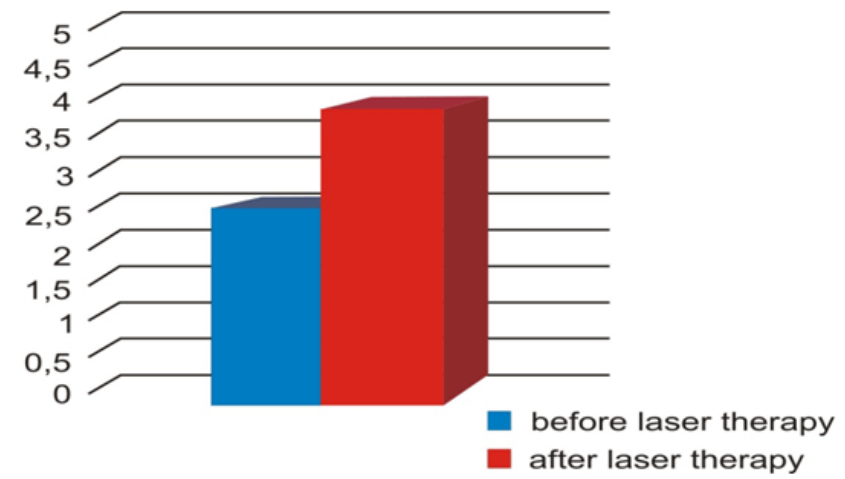

Chart 1: Appearance' Self Esteem, before and after laser therapy 


\section{Discussion}

ASE assessment scale distribution in the1st and the 2nd measurement (before and after $\mathrm{CO}_{2}$ laser therapy, respectively) is close to Normal distribution. Coefficient of internal consistency (Cronbach's alpha) for the first and the second measurement was 0.81 , and 0.61 , respectively. No gender differences observed in both $1^{\text {st }}$ and $2^{\text {nd }}$ measurements: $(M=2.45, S D=0,56)$ female $(\mathrm{M}=2.59, \mathrm{SD}=0.57) ; \mathrm{t}=-1.077, \mathrm{p}=0.284$ and males $(\mathrm{M}=3.86$, $\mathrm{SD}=0.28)$, females $(\mathrm{M}=3.86, \mathrm{SD}=0.38) ; \mathrm{t}=0.077, \mathrm{p}=0.939$ A complete aesthetic $\mathrm{CO}_{2}$ laser removal of multiple sebborheic keratoses from the face and trunk improves appearance related self-esteem.

Clinical results prove laser thermolysis method is more effective method than traditional methods of SK removal (electrocoagulation, cryodestruction, chemical destruction, curettage and surgery), and guarantees aesthetics of removing SK without visible scarring.

\section{Conclusions}

Described original $\mathrm{CO}_{2}$ laser treatment strategy serves as a practical tool in aesthetic removal of multiple seborrheic keratoses. Original study findings provide useful data on effects of removal of multiple seborrheic keratosis on appearance' selfesteem of those affected by MSK. Results indicate that issues in psycho-social functioning for those with skin problems are to be of particular importance, and interest to dermatology specialists. Psychological mechanisms of patient appearance perception hence, need to be studied further in terms of better assessing, prolonging and enhancing well-being of patients with skin diseases. Understanding of psychological mechanisms of the physical self additionally contributes in establishing effective communication, and collaboration between the patient and the dermatologist.

\section{Abbreviations}

SK: Seborrheic Keratosis

MSK: Multiple Seborrheic Keratosis

$\mathbf{C O}_{2}$ : Carbon Dioxide

ASE: Appearance Self-Esteem

DPN: Dermatosis Papulosa Nigra

\section{References}

1. Araya M, Kulthanan K, Jiamton S. Clinical Characteristics and Quality of Life of Seborrheic Dermatitis Patients in a Tropical Country. Indian J Dermatol. 2015;60(5):519. doi: 10.4103/0019-5154.164410

2. Balabanova, M. Perception of Appearance Changes post Lasertherapy and Psychosocial Functioning. Doctoral Dissertation. VFU Chernorizetz Hrabar. 2018;

3. Balabanova M and Penev J. Skin \& Psych Relationships. Paper. Int. Scientific Conference in Applied Psychology: opportunities and perspectives, VFU Chernorizetz Hrabar, 2018;

4. Balabanova $\mathrm{M}$ and Penev J. Implications of Negative Body Image on Social Interaction. Paper. Int. Scientific Conference in Applied Psychology: opportunities and perspectives, VFU Chernorizetz Hrabar, 2017;

5. Gill D, Dorevitch A, Marks R. The Prevalence of Seborrheic Keratoses in People Aged 15 to 30 YearsIs the Term Senile Keratosis Redundant?. Arch Dermatol. 2000;136(6): 759-762.doi:10.1001/ archderm.136.6.759

6. Monali J, Kulkarni A, Feldman SR, Balkrishnan R. Quality of life in patients with psoriasis. Health Qual Life Outcomes. 2006; 4:35. doi: 10.1186/1477-7525-4-35

7. Penev J. Laser Ablation of Seborrheic Verruca - a therapeutic approach for an aesthetic result . Paper. Dermatological View, Varna Spring Dermatology Days Int. Conference, Apr. 2018

8. Penev J. Body rejuvenation and improvement in quality of life after laser ablation of all benign pathological lesions in several therapeutic sessions. Paper. Dermatological View, Varna Spring Dermatology Days Int. Conference, Apr. 2017

9. Szepietowski JC, Reich A, Wesolowska-Szepietowska E, Baran E. Quality of life in patients suffering from seborrheic dermatitis: influence of age, gender and education level. Mycoses. 2009;52(4):357-363. doi: 10.1111/j.1439-0507.2008.01624.x

10. Kraaimaat FW, Kerkhof C, Weel C, Duller P, Valk P G M, Hoogen .Psychosocial well-being of patients with skin diseases in general practice.Journal of European Academy of Dermatol Venereol. 2007;21(5):662-668. DOI: 10.1111/j.1468-3083.2007.02049.x

11. Wollina U. Recent advances in managing and understanding seborrheic keratosis. F1000 Research. 2019 ;28 (8):doi: 10.12688/ f1000research.18983.1 